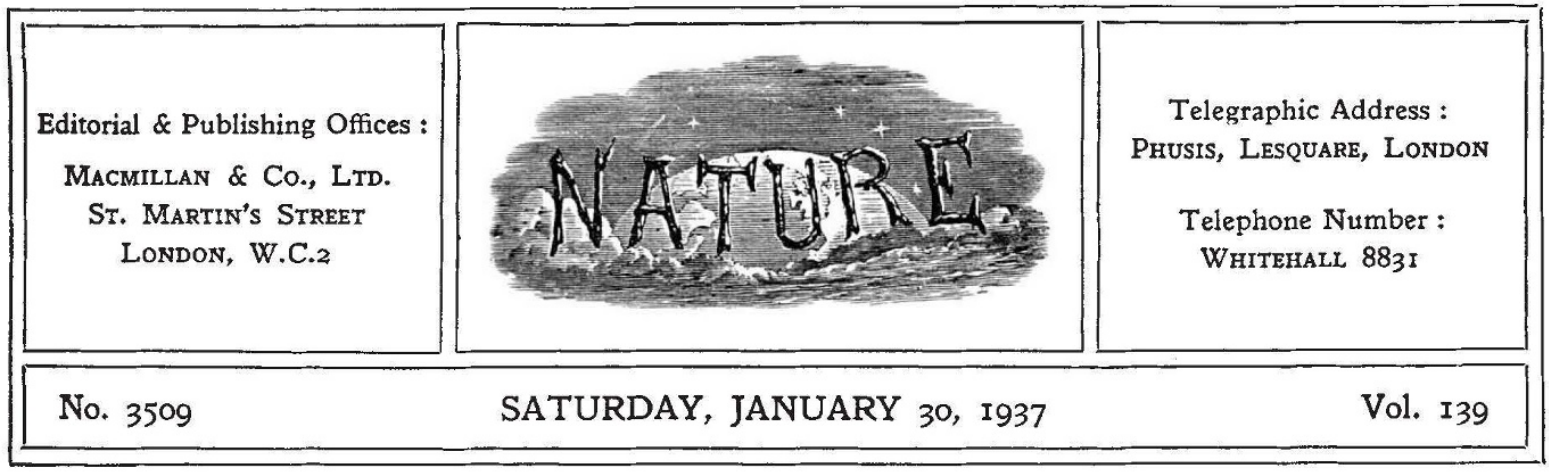

\title{
Native Races and Nationalism in Africa
}

$\mathrm{T}$ HE development of nationalist ideas as an effective political force in eastern Asia and, more particularly, in India, has afforded a justification for those who hold that a like course of events may be anticipated sooner or later among the native races of Africa. Negro Africa, that is, Africa south of the Sahara, they would maintain, is an unsurpassed forcing house for ideas such as have inspired the more loudly vocal element in recent and current political agitation in India. For these regions of Africa are the meeting-place of two utterly diverse races, white and black, who are poles apart in physical character, mental outlook, tradition and culture, and of whom, while one, everywhere numerically the inferior, is politically and economically dominant, the other is rapidly transcending the limitations as well as outgrowing the opportunities of tribal code and indigenous culture. The natural division thus existing in the community, and reinforced by social and political barriers, must inevitably, it is held, give rise to a group consciousness on the part of native peoples, which unless checked or diverted, will tend to the more unstable and politically dangerous forms of racialism and nationalistic ideation.

Fortunately, diagnosis of possibilities in the trend of the development of native outlook is not entirely a matter of speculation. In Africa south of the Zambezi, where conditions are most favourable to the rise of nationalism, the Union of South Africa has for a guide in its approach to the native question experience of native reaction to a variety of European contacts extending over a long period of time; while the mining industry for nearly half a century has brought native administration into contact with the problems which arise out of the employment of labour on a large scale. But we may go even a stage further than general considerations, which emerge from an investigation of past history, and lay our finger on specific movements and events of recent occurrence pointing in the direction of an emergence of a sense of the solidarity of native interests, which if racial rather than national in character, is none the less significant of growth towards a feeling of community and of the power of a common direction in action and sentiment. This at least would appear to be the salient lesson to be learned from the valuable survey of recent happenings and tendencies in South, East, and West Africa, given by Lord Hailey in his address on "Nationalism in Africa" before the Royal Empire Society on January 19, when he summarized his study of the situation, as well as the results of observations made on his recent tour through Africa. His conclusions were the more worthy of careful note, since he was at pains to point out that while well aware of the opinion which views, not without alarm, the possible trend of development in native African political opinion towards nationalism, he himself is not among the prophets, but merely records as an observer.

In another matter Lord Hailey had taken his stand with no little wisdom. He refrained from any attempt to define nationalism, assuming that the character of this political and economic attitude or doctrine was sufficiently familiar to his audience to need no definition; but he indicated that he meant by 'nationalism' the governing force of a uniting will directed to national advancement in combination with certain social and economic factors, such as had manifested itself in European history during the period beginning in 
the eighteenth century and had appeared recently in Asia. Taking advantage of this elasticity in his point of view, he was able to bring under consideration aspects of native activity which on a stricter interpretation of the term might have to be excluded, and while admitting variety in the meaning of 'nationalism', enabled him to seek for such evidence as would indicate that native self-consciousness was becoming an "effective factor"-a new phenomenon, creating a new problem. Hence, as he pointed out, it is not merely opposition to Government that gives a movement significance in this sense, but rather such events as would testify to the growth of racial feeling or afford proof that the natives of different tribes or areas could combine on a common basis. For such an exhibition of growing consciousness it is natural to look to circumstances in which the material factor is more prominent, as for example in the curtailment of land, or the creation of unequal economic conditions. In taking, therefore, the Union of South Africa as his natural starting point, Lord Hailey is in accord with the view that the occasion and opportunity for the development of nationalism will most probably be found south of the Zambezi.

Before passing on to note some of the more important events and tendencies, to which in Lord Hailey's opinion this special significance may be attached, it is perhaps worth while to point out that whereas the white population of the Union of South Africa is determined at all costs to protect from native intrusion the white civilization which has been built up there, the native population, on its side, at least in so far as represented by the more thoughtful and influential of its leaders, is equally convinced that segregation and conservation of the elements of native solidarity is fully as necessary for the well-being of the native community. It is from the promoters of this movement and from this line of thought that nationalism in South Africa, if or when it comes, will draw its strength. On the other hand, in the labour movements to which Lord Hailey referred, it is perhaps not so much racial feeling as the colour bar which has been operative. The two are by no means identical; and in view of the wide area and varied tribal units from which recruits are drawn, labour perhaps has been often of too heterogeneous a character to warrant it being regarded as of great significance in a racial sense, although naturally of evidential value in relation to the ability of the native to combine.
It was this heterogeneity, perhaps, as much as any single factor, which led to the collapse of the famous (or infamous) Industrial and Commerical Union, which was initiated under Soviet influence and at one time numbered 250,000 members. Nevertheless, it has to be remembered that it was held by those who investigated the movement officially after the riots at Port Elizabeth in 1922 that it did afford some evidence of Bantu racial consciousness. The members, however, were either detribalized, or not at the moment under tribal control, the mine labour, numerically the most important, being, as already mentioned, recruited from tribes at a distance. It is also to be noted in this connexion that in East Africa such trouble as has occurred from time to time in riots at Nairobi and elsewhere, as a rule, has been caused for the most part by detribalized natives. Except under abnormal conditions, tribal institutions favour the settled order. This is a fact which should not be overlooked in estimating the character and motives of movements which appear to lead in the direction of nationalism.

Of the circumstances affecting the solidarity of the native communities in the Union, by far the most important has been the question of land. It touched every member of tribal and rural community alike. As vital to native existence, it unified Bantu opinion throughout the Union in a common cause and to a degree scarcely witnessed before if at all. So far back as 1913, when Botha's land legislation was introduced into Parliament, this question was responsible for the formation of the short-lived African National Congress. It endured as a source of unrest until further legislation in 1936, when the question was complicated by the proposal, which was carried, to abolish the Cape Franchise, the restricted but highly valued native vote. Although, as Lord Hailey points out, this in itself produced no lasting effect or permanent organization, it did much to promote unity by bringing together members of the native races for discussion and protest with a common aim. An African convention in 1935 set up an organization to achieve reforms by constitutional means, but it is too soon to pronounce on its merits.

While Lord Hailey does not appear disposed to attach too great weight to the movement towards Separatist Churches, such movements are frequently an outlet, sometimes a source and inspiration, for nationalist movements of a formidable character. One of the most serious 
difficulties of the Kenya administration which assumed something like nationalist proportions was the Kikuyu female circumcision controversy.

A brief reference to conditions in other parts of Africa must suffice. In East Africa, circumstances not unlike those of South Africa, though on much smaller scale, have produced similar reactions in the formation of associations for the advancement and formulation of native interests. In the older colonies of West Africa, the education of natives on European lines has produced an intellectual class which seeks wider recognition of native rights through existing constitutional means. Nor is it necessary that the French and Belgian colonial empires should detain us, for in the former, as Lord Hailey points out, everything is directed to France--an orientation which finds expression in the representation of colonial interests in the legislature of the mother country by a native deputy; while under Belgian rule, both in the colony and the mandated territory, commercial rather than political development of native resources is the aim. Lord Hailey might perhaps have added that under French rule, in actual practice something very much in the nature of the indirect rule of the British dependencies is the result.

In pursuit of his intention to act as an observer only, Lord Hailey, while noting that the trend towards the nationalist idea is approved by some, but strongly condemned by others, made no attempt to sit in judgment. Nevertheless, the question is one that will be posed by the mere efflux of time, and insistently will demand an answer. It will have been noted that the movements to which attention has been directed have all been separatist in character. They have emphasized the fission in the community, which results from the association of black and white. Is this inevitable? This raises a large question, which involves the whole future of the African races. It is obvious that neither under the policy of indirect rule nor of segregation, as in South Africa, will the African peoples stand still. The rapid advances of the last few years are a sufficient negation of any such conception. It is the belief of those who hold to the advantages of indirect rule, as well as of those who see the possibilities of advance under other systems, that the future of Africa lies in the co-operation of the two races. For this, and to determine the lines upon which it should be pursued, the assistance of the more advanced and intellectual members of the African peoples must be secured. If, as many think, the movement towards racial or national self-consciousness is an inevitable phase of development in Africa, time should be taken by the forelock, and this force, great as it must and will be, should be harnessed to the constructive task of building up a united community, rather than weakening the social structure of Africa by setting a gulf between the elements which should co-operate.

\section{Unsolved Soil Problems}

Fifty Years of Field Experiments at the Woburn Experimental Station

By Sir E. John Russell and Dr. J. A. Voelcker; with a Statistical Report by W. G. Cochran. (Rothamsted Monographs on Agricultural Science.) Pp. $x v i+392+4$ plates. (London, New York and Toronto : Longmans, Green and Co., Ltd., 1936.) 21s. net.

CROP husbandry, the first occupation of man, $G$ which must ever remain essential to the maintenance of human life, has been pursued through all the ages as an art and a craft. The bearing of science upon it is a very recent develop. ment which is probably still only in its initial stages. Crops grow in vital association with two media, the air and the soil. It is barely a century ago that, following the discovery of photo- synthesis, the main facts about the relationship of the crop to the air became generally known. The essential facts about the relationship of the crop to the soil are still clouded in mystery. In spite of all the development in the study of plants on one hand and of soils on the other, very little is known of the relationship of one to the other, and we are still largely dependent upon empirical experiments in order to determine the effect upon the plant of any particular treatment of the soil. Moreover, as this account of the Woburn experiments shows very clearly, the successful conduct of empirical experiments is beset with great difficulties.

Field experiments to test the effect upon the crop of applications to the soil began about a century ago with the work of Boussingault in France. The now classical Rothamsted experiments 